\title{
Model for Development of Mass Communication Technology Graduates' Desired Characteristics Based on Thai Qualifications Framework for Higher Education
}

\author{
Chantana Papattha, Prachyanun Nilsook, and Namon Jeerungsuwan
}

\begin{abstract}
The purposes of the research study were 1) to investigate factors essential for the development of mass communication technology graduates' desired characteristics based on Thai qualifications framework for higher education (TQF for HEd) in order to develop learning process of mass communication technology students, 2) to design a model for development of graduates' characteristics, and 3) to evaluate the developed model. Three steps of the research study were: 1) reviewing literature to analyze and synthesize the factors essential to the model, 2) designing the model, and 3) evaluating the model. The sample group included nine experts who specialized in education and technology, graduates' characteristics, Thai qualifications framework for higher education, and mass communication technology education. The first research result revealed that there were seven factors essential for developing graduates' characteristics: content skills, communication skills, technology skills, collaboration skills, thinking skills, professional and practice skills, and morality and ethics skills. The second research result showed that the model consisted of seven components and 27 subcomponents. The final research result reported that nine experts agreed that the model was appropriate in the highest level on all three aspects and the overall picture of the model.
\end{abstract}

Index Terms-Model of graduates' characteristics, Thai qualifications framework (TQF), higher education, mass communication technology.

\section{INTRODUCTION}

Quality Education Management was essential for the growth of every nation due to the reason that education provides foundation for the growth in social, economic, political and technology sectors [1]. Considering Thailand revolutionized the country's educational system in 2011 and the better educational direction known as the $21^{\text {st }}$ Century Skills that focused on individual skillset of the students, the focus of educational development should be on critical thinking, communication, collaboration, and creativity known as the 4Cs [2]. The Thai National Education Act B.E. 2542 (A.C.1999) and Amendments (Second National Education Act B.E. (2002) imposed an education reform

Manuscript received March 14, 2014; revised May 27, 2014.

Chantana Papattha is with the Department of Multimedia Technology, Faculty of Mass Communication Technology, Rajamangala University of Technology Phra Nakhon, Thailand (e-mail: chantana.p@rmutp.ac.th).

Prachyanun Nilsook is with Division of Information and Communication Technology for Education, Faculty of Technical Education, King Mongkut's University of Technology North Bangkok (KMUTNB), Thailand.

Namon Jeerungsuwan is with Department of Technological Education, Faculty of Technical Education, King Mongkut's University of Technology North Bangkok, Thailand. stressing the curriculum development and modification of teaching methods to develop a students' critical idea, solution skills, and the awareness of the value of culture.

Ref. [3] office of the Higher Education Commission (HEC) acts as a regulatory agency to promote the operation of higher education institutions Thai Qualifications Framework for Higher Education: TQF for HEd. The TQF for HEd was the measurement to drive the policy in the National Education Act B.E. 2542 (1999) and Amendments [Second National Education Act B.E. (2002)]. Six learning outcomes included; teaching and evaluation strategies in TQF: Morals and Ethics, Knowledge, Cognitive Skills, Interpersonal Skills and Responsibilities, Numerical Analysis Skills, Communication and Information Technology Skills, and Psychomotor Domain Skills. Ref. [1] the HEC had set the standard professional qualification and adopted the standard across the country.

One responsibility of higher education institute was to provide of education based on TQF for HEd, however in Thailand there was no designated National Qualification Framework for Higher Education degree in mass communication. With this responsibility, the Faculty of Mass Communication Technology (MCT), Rajamangala University of Technology Phra Nakhon (RMUTP) education developed technology curriculum based on six standards in TQF for HEd [4]. The MCT committee on mass communication technology wanted to define standard qualifications framework of professional technology communication. The study was prepared to find factors essential for development of graduates' characteristics based on TQF for HEd to develop a standard qualifications framework of professional technology communication [5].

\section{OBJective OF THE STUDY}

The objectives of the study were 1) to investigate factors essential for the development of mass communication technology graduates' desired characteristics based on Thai qualifications framework for higher education in order to develop learning process of mass communication technology students, 2) to design a model of mass communication technology graduates' desired characteristics, and 3) to evaluate the model.

\section{RESEARCH METHODS}

Three Steps in the Study

Step 1: Analyzing factors essential for development of 
mass communication technology graduates' desired characteristics based on TQF for HEd. Five theories and concepts: 1) $21^{\text {st }}$ Century Student Outcome and Support Systems, 2) Graduates' characteristics based on TQF for HEd, 3) Learning standard based on TQF for HEd of RMUTP, 4) Learning standard based on TQF for HEd in bachelor's degree Technology (Mass Communication Technology), Rajamangala University of Technology Phra Nakhon (RMUTP), and 5) Graduates' desired characteristics of RMUTP.

Step 2: Designing the model of mass communication technology graduates' desired characteristics based on TQF for HEd: Factors essential from step 1 to develop the model for developing of mass communication technology graduates' desired characteristics.

Step 3: Evaluating the model of mass communication technology graduates' desired characteristics based on TQF for HEd: Nine experts who were specialists in education and technology, graduates' desired characteristics, TQF for
Higher education, and mass communication technology management.

Questionnaires were employed to collect data which were analyzed to find arithmetic mean and standard division. The results were presented in table followed with description.

\section{RESUlts}

Step 1 results: There were six factors essential for the development of mass communication technology graduates' desired characteristics based on TQF for HEd.

The first factor was content skills: General Courses (Thai language, Foreign Language, Social and Humanities, Mathematics and Science, and Physical Education and Recreation), Main Courses Subjects (Main Subjects, Major Subjects, and Main Elective Subjects), and Free Elective Subjects.

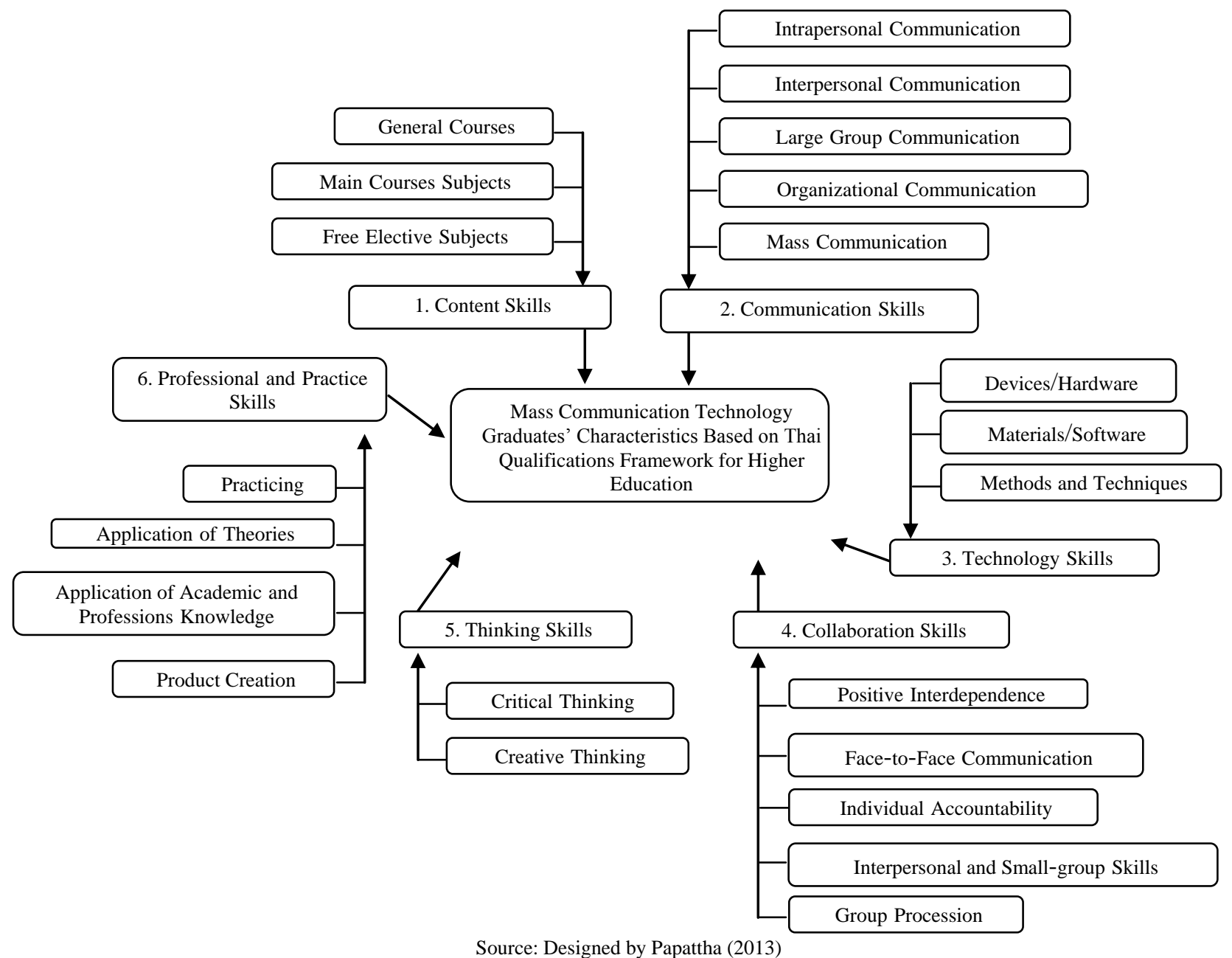

Fig. 1. Mind map of factors essential for development of mass communication technology graduates' desired characteristics based on TQF for HEd.

The second factor was communication skills: Intrapersonal Communication, Interpersonal Communication, Large Group Communication, Organizational Communication, and Mass Communication.

The third factor was technology skills: Devices and Hardware, Materials and Software, and Methods and Techniques. Graduates should be able to assess and use technology of the three aspects. They should be able to integrate those skills to work with others effectively.

The fourth factor was collaboration skills: Positive Interdependence, Face-to-Face, Individual Accountability, and Group Procession.

The fifth factor was analytical thinking skills: Creativity and Critical Thinking.

The sixth factor was professional and practice skills: Practicing, Application of Theories, Application of 
Academic and Professions Knowledge and Product Creation.

Factors essential for development of graduates' characteristics based on TQF for HEd presented mind map relation factors in Fig. 1.

Step 2 results: Draft of the MCTGC TQF model applied from related factors essential to develop desirable characteristics consisting of various subjects shown in Fig. 2.

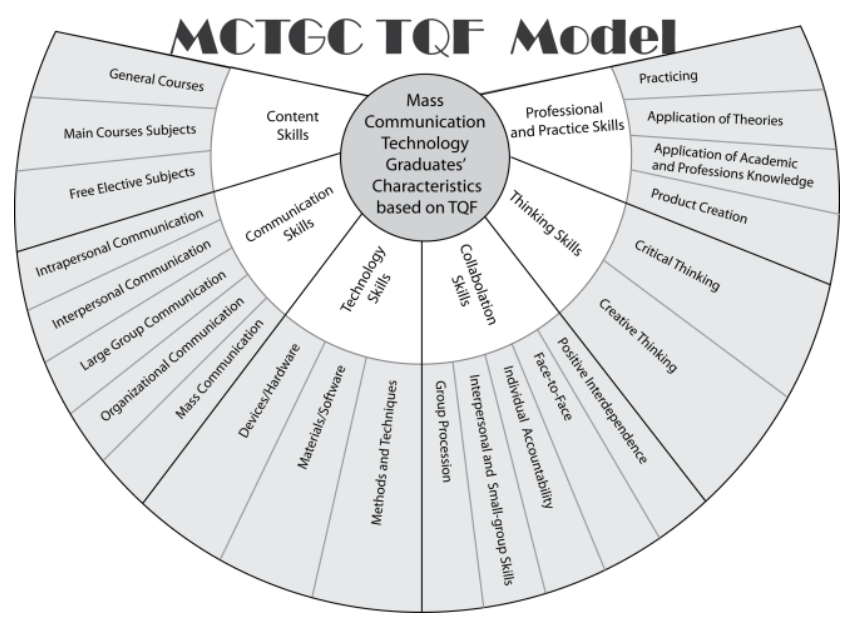

Source: Designed by Papattha (2013)

Fig. 2. Draft of the MCTGC TQF model.

Step 3 results: Evaluating the model based on TQF for HEd.

Part 1: Theories and concepts for the application on communication technology graduates' characteristics based on TQF for HEd.

TABLE I: APPRORIATENESS OF THEORIES AND CONCEPTS IN MCTGC TQF MODEL

\begin{tabular}{lccc}
\hline \multicolumn{1}{c}{ List of items } & $\bar{x}$ & S.D. & Level \\
\hline $\begin{array}{l}\text { Theories and concepts for the analysis on } \\
\text { development factors of communication } \\
\text { technology graduates' characteristics and } \\
\text { design MCTGC TQF model }\end{array}$ & 4.49 & 0.51 & Very high \\
$\begin{array}{l}\text { Six factors for mass communication } \\
\text { technology graduates' characteristics } \\
\text { based on TQF for HEd (Content Skills, } \\
\text { Communication Skills, Technology Skills, } \\
\text { Collaboration Skills, Thinking Skills, and }\end{array}$ & 4.63 & 0.49 & Very high \\
Professional and Practice Skills) & & & \\
\hline \multicolumn{1}{c}{ Overall Appropriateness } & & & \\
\hline \hline
\end{tabular}

TABLE II: SUITABILITY EVALUATION OF FACTORS IN MCTGC TQF MODEL

\begin{tabular}{lccc}
\hline \multicolumn{1}{c}{ List of items } & $\bar{x}$ & S.D. & Level \\
\hline Content Skills & 4.52 & 0.51 & Very high \\
Communication Skills & 4.56 & 0.50 & Very high \\
Technology Skills & 4.56 & 0.51 & Very high \\
Collaboration Skills & 4.47 & 0.55 & Very high \\
Thinking Skills & 4.50 & 0.51 & Very high \\
Professional and Practice Skills & 4.47 & 0.56 & Very high \\
\hline \multicolumn{1}{c}{ Overall Appropriateness } & 4.51 & 0.52 & Very high \\
\hline \hline
\end{tabular}

Table I shows suitability evaluation of theories and concepts to apply in MCTGC TQF model overall appropriateness which was in very high level $(\bar{x}=4.57$, S.D.=0.49). The theories and concepts to MCTGC TQF model had suitability in very high level ( $\bar{x}=4.63$, S.D. $=0.49$ ). Six factors for mass communication technology graduates' characteristics based on TQF for HEd (Content Skills, Communication Skills, Technology Skills, Collaboration Skills, Thinking Skills, and Professional and Practice Skills) had suitability in highest level ( $\bar{x}=4.63$, S.D. $=0.49$ ).
Part 2: Factors in MCTGC TQF model.

Table II shows suitability evaluation of factors to develop mass communication technology graduates' characteristics based on TQF for HEd overall appropriateness in very high level ( $\bar{x}=4.51$, S.D. $=0.52$ ). Six factors had evaluation all factors in very high level: Content Skills ( $\bar{x}=4.52$, S.D.=0.51), Communication Skills ( $\bar{x}=4.56$, S.D.=0.50), Technology Skills ( $\bar{x}=4.56$, S.D. $=0.51)$, Collaboration Skills ( $\bar{x}=4.47$, S.D. $=0.55$ ), Thinking Skills ( $\bar{x}=4.50$, S.D. $=0.51)$, and Professional and Practice Skills $(\bar{x}=4.47$, S.D.=0.56).

Part 3: Designing and applying MCTGC TQF model to develop Mass Communication Technology students

TABLE III: SUITABILITY EVALUATION OF DESIGNING AND APPLYING THE MCTGC TQF MODEL TO DEVELOP MASS COMMUNICATION TECHNOLOGY STUDENTS

\begin{tabular}{|c|c|c|c|}
\hline List of items & $\bar{x}$ & S.D. & Level \\
\hline $\begin{array}{l}\text { Reviewing literature to analyze and } \\
\text { synthesize the factors essential to the } \\
\text { model }\end{array}$ & 4.56 & 0.53 & Very high \\
\hline $\begin{array}{l}\text { Designing the MCTGC TQF model } \\
\text { were composed of the purpose model }\end{array}$ & 4.44 & 0.53 & Very high \\
\hline $\begin{array}{l}\text { The MCTGC TQF model used to } \\
\text { develop mass communication } \\
\text { technology }\end{array}$ & 4.44 & 0.53 & Very high \\
\hline Overall Appropriateness & 4.48 & 0.51 & Very high \\
\hline
\end{tabular}

Table III shows appropriation of designing and applying the MCTCG TQF model overall appropriateness in very high ( $\bar{x}=4.48$, S.D. $=0.51$ ). Reviewing literature to analyze and synthesize the factors essential to the model had suitability in very high level ( $\bar{x}=4.56$, S.D. $=0.53$ ). Designing the MCTGC TQF model were composed of the purpose model had suitability in very high level ( $\bar{x}=4.44$, S.D. $=0.53)$. The MCTGC TQF model used to develop mass communication technology had suitability in very high level $(\bar{x}=4.44$, S.D. $=0.53$ ).

Nine experts provide the following recommendations for improving in MCTCG TQF model was: 1) add morality and ethics factors, 2) group three elements in content factor was content based on curriculum, 3) add interdisciplinary content in content factor, 4) add basic communication skills: listening skill, speaking skill, reading skill, and writhing skill, and 5) add system thinking skill.

The new model consists of seven factors (content skills, communication skills, technology skills, collaboration skills, thinking skills, professional and practice skills and morality and ethic skills) which have been improved according to nine expert's comments and literature review.

The seventh factor was morality and ethics skills had five elements: Decency, Discipline and punctuality, Self and Social Responsibility, democracy, and Mass Communication Professional Ethics.

The first factor was content skills had two elements: Content based on Curriculum and Interdisciplinary Content (Access Data Source, Using Massage, and Adaptive Content).

The second factor was communication skills had five elements: Basic Communication Skills, Communication Language Skills, Intrapersonal Communication, 
Communication, and Mass Communication.

The fifth factor was thinking skills had three elements: System Thinking, Critical Thinking, and Creative Thinking.
Factors essential presenting mind map relation factors in Fig. 3 to develop the revised MCTGC TQF model.

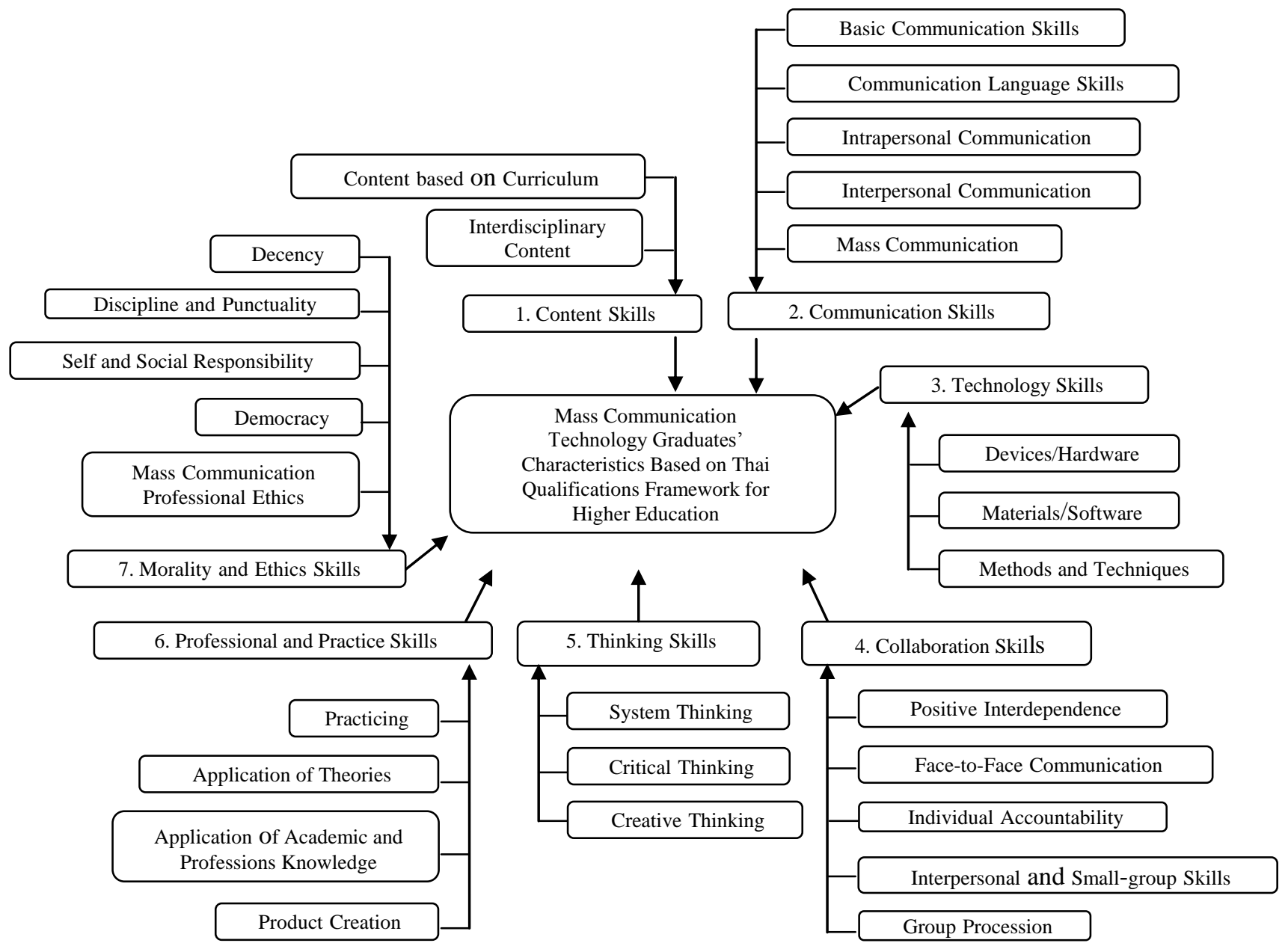

Source: Design by Papattha (2013)

Fig. 3. Mind map of factors essential to develop the revised MCTGC TQF model improved by nine experts.

Fig. 3 shows mind map of factors essential which had been improved by nine expert's comments to develop revised MCTGC TQF model. The revised MCTGC TQF model improved by nine exports presented in Fig. 4.

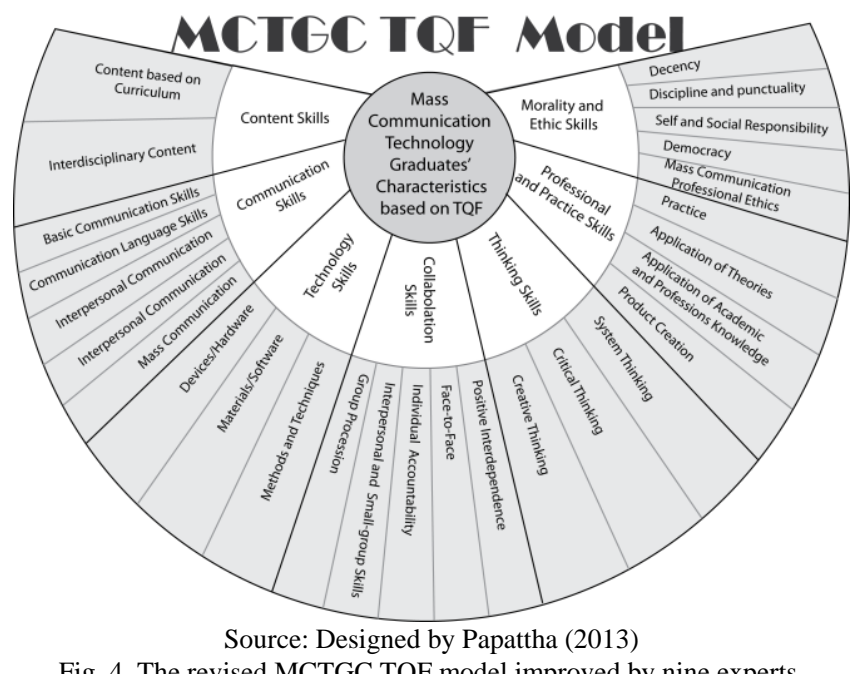

Fig. 4. The revised MCTGC TQF model improved by nine experts.

Fig. 4 showed a revised MCTGC TQF model. This model had seven factors.

Content skills comprised two elements: 1) Content based on Curriculum: General Courses (Thai Language, Foreign Language, Social and Humanities, Mathematics and Science, and Physical Education and Recreation), Main Courses Subjects (Main subjects, Major Subjects, and Main Elective Subjects), and Free Elective Subjects, and 2) Interdisciplinary Content: Access Data Source, Using Massage, and Adaptive Content.

Communication skills consisted of five elements: 1) Basic Communication Skills (Listening, Speaking, Reading, and Writing), 2) Communication Language Skills (Thai Language and Foreign Language), 3) Intrapersonal Communication, 4) Interpersonal Communication (Face to Face Communication, Small Group Communication, Large Group Communication, and Organizational Communication), and 5) Mass Communication (Newspaper, Magazine and Journalism, Radio Broadcasting, and Television Broadcasting).

Technology Skills comprised three elements: 1) Devices/Hardware, 2) Materials/Software, and Methods and Techniques.

Collaboration skills consisted of five elements: 1) Positive Interdependence, 2) Face-to-Face, 3) Individual Accountability, 4) Interpersonal and Small-group Skills, and

5) Group Procession.

Thinking Skills consisted of three elements: 1) System Thinking, 2) Critical Thinking, and 3) Creative Thinking. 
Professional and Practice Skills included four elements: 1) Practicing, 2) Application of Theories, 3) Application of Academic and Professions Knowledge, and 4) Product Creation.

Morality and Ethics skills comprised five elements: 1) Decency, 2) Discipline and punctuality, 3) Self and Social Responsibility, 4) Democracy, and 5) Mass Communication Processional Ethics.

\section{Discussions}

The essential factors for mass communication technology graduates' characteristic based on TQF for HEd constituted seven factors: Content skills, communication skills, technology skills, corroboration skills, thinking skills, professional and practice skills and morality and entices. The result of this study on factors of graduates' characteristic as TQF for HEd [3] could be concluded as follows:

The graduates should be able to 1) have knowledge in concept and theories based on professional and interdisciplinary content to apply in their life, 2) apply and analyze skills in mathematics, and statistic to problem solving, and 3) apply communication skills in work and life. Five skills based on learning outcomes, teaching and evaluation strategies in TQF for HEd include Morals and Ethics, Knowledge, Cognitive Skills, Interpersonal Skills and Responsibilities, Numerical Analysis, and Communication and Information Technology Skills.

Theories and concept analysis revealed that five elements to develop mass communication technology graduates' characteristic was in highest level. The first element was $21^{\text {st }}$ Century Student Outcome and Support Systems [6]. Partnership for $21^{\text {st }}$ Century Skills presented $21^{\text {st }}$ century student skills including thinking, learning, working, problem solving, communicating, and Collaboration [2]. The result of graduates' characteristic complied with TQF for HEd under the National Education Act B.E. 2542 (1999) and Amendments (Second National Education Act B.E. (2002)) [3].

The evaluation on appropriateness of designing and applying the MCTGC TQF model and evaluation of design and use MCTGC TQF to develop MCT students was overall in very high level. This model could develop standard qualifications framework of professional technology communication based on TQF for HEd. [2] The Higher Education Commission assigned principle and objectives of TQF as follows: The first result was on the device and material to drive quality and education standard. The second result was on the application TQF with education management via curriculum development, learning process, and achievement evaluation of students. The third result of goal was to develop graduate characteristic based on TQF for HEd in qualification, department, and occupation. The fourth result of platform was to design learning process such as planning to learn, improving to process leaning, and developing education system. The fifth result relating to education was design and develops lifelong learning system. The sixth result factors were support foreign education. The seventh result factors were to control of graduate quality. Finally, students consisted of the standard education based on
TQF for HEd and standard as in quality assessment education.

\section{CONCLUSION}

Finally, the MCTGC TQF model consisted of seven factors components and 27 subcomponents for developing mass communication technology graduates' desired characteristics: content skills, communication skills, technology skills, collaboration skills, thinking skills, professional and practice skills, and morality and ethics skills.

\section{ACKNOWLEDGEMENT}

The authors are grateful for the financial support of the Faculty of Mass Communication Technology, Rajamangala University of Technology Phra Nakhon, Thailand. The authors also thanks for the supports of King Mongkut's University of Technology North Bangkok, Thailand.

\section{REFERENCES}

[1] Ministry of Education, Information and Communication Technology for Education Model Scheme of Ministry of Education, Bangkok: Office of the Permanent Secretary, Ministry of Education, 2011, pp. 4-6.

[2] Partnership for $21^{\text {st }}$ Century Skills. (March 2011). Framework for $21^{\text {st }}$ Century Learning. [Online]. Available: http://www.p21.org/storage/documents/1._p21_framework_2-pager. pdf

[3] The Higher Education Commission, Thai Qualifications Framework for Higher Education 2009 and Regulation, Bangkok: The Higher Education Commission, 2009, pp. 19-20, 53.

[4] Rajamangala University of Technology Phra Nakhon, Rajamangala University of Technology Phra Nakhon Notice: Subject Learning Standard based on Thai Qualifications Framework for Higher Education, Bangkok: Rajamangala University of Technology Phra Nakorn, 2010, p. 2.

[5] Faculty of Mass Communication Technology, Technology Curriculum 2012 (Improved), Bangkok: Mass Communication Technology, Rajamangala University of Technology Phra Nakhon, 2012, pp. 4-5.

[6] W. Wongkijroongruang and A. Jittareak, New skills in the future. Education for the $21^{\text {st }}$ Century: $21^{\text {st }}$ Century Skills Rethinking How Students Learn, Bangkok: Openworlds, 2011, p. 40.

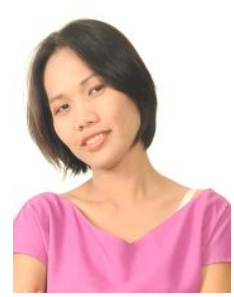

Chantana Papattha is studying for the doctor of philosophy in information and communication technology for education, Faculty of Technical Education, King Mongkut's University of Technology North Bangkok, Thailand. She is currently a full time lecturer at the Department of Multimedia Technology, Faculty of Mass Communication Technology, Rajamangala University of Technology Phra Nakhon, Thailand. She obtained the bachelor's degree in computer education, from Faculty of Education, Dhonburi Rajabhat Institute, and Thailand in 2004 and received master's degree in technology computer from King Mongkut's Institute of Technology North Bangkok, Thailand in 2006.

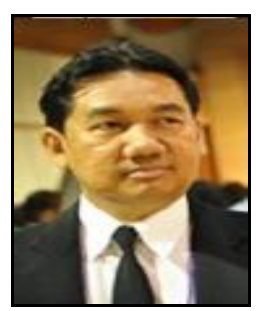

Prachyanun Nilsook is an associate professor at Division of Information and Communication Technology for Education, Faculty of Technical Education, King Mongkut's University of Technology North Bangkok (KMUTNB), and Thailand. He received the B.Ed. degree in audio-visual education, from the Faculty of Education, Ramkhamhang University, Thailand in 1989. He obtained his M.Ed. degree in educational technology from Faculty of Education, Srinakarinwirot University, Thailand in 1995, and received Ph.D. degree in educational communications and technology from Faculty of Education, Chulalongkorn University in 2001. 2001- Present, he works in the field of information and communication technology in education. He has experience in many positions such as the dean, Faculty of Technical Education, Samutsongkhram Technical Collage, 
Faculty of Information and Communication Technology, Samutsongkhram Technical Collage, and the director of Vocational Education Technology Research Center. He received National Teachers Award of the Year in Higher Education 2004 from National Teacher Council, Ministry of Education, and Thailand. He is a membership of Professional Societies in Association for Educational Technology of Thailand (AETT).

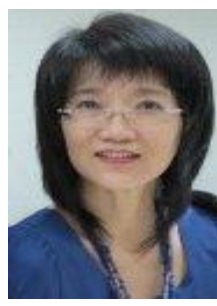

Namon Jeerungsuwan is currently a full time associate professor at the Department of Technological Education, Faculty of Technical Education, King Mongkut's University of Technology North Bangkok, Thailand. She has held a position of the director of $\mathrm{Ph} . \mathrm{D}$. Program in information and communication technology for education since 2011. She was the head of the Department of Educational Technology, KMUTNB, during 2002-2006. She received her doctoral degree in instructional design and development from University of South Alabama and her master's degree in Educational Media from Western Oregon University. She also received the award of the Royal Tha Government Scholarship and the award of Kappa Delta Phi during she was pursuing the doctoral degree in the USA. Her past experience included director of Online Learning Center, KMUTNB. Currently, she is the executive committee of the e-learning Association of Thailand, the Educational Technology Association of Thailand, the associate editor of International Journal of Technology, Knowledge, and Society, and the member of IEEE society. 